\title{
Staging in Patients with Small-Cell Lung Carcinoma; PET-CT versus Standard Staging Procedures
}

\author{
Burcu Yalçın¹ ${ }^{1}$ Ufuk Yılmaz ${ }^{1}$, Tuğçe Çiftçi² ${ }^{2}$ İbrahim Yügünt², Salih Akşit ${ }^{3}$, \\ Bahri Gümüş̧, Hakan Koparal²
}

${ }^{1}$ Department of Chest Diseases, Dr. Suat Seren Chest Disease and Surgery Training and Research Hospital, İzmir, Turkey ${ }^{2}$ Department of Nuclear Medicine, Dr. Suat Seren Chest Disease and Surgery Training and Research Hospital, Izmir, Turkey ${ }^{3}$ Department of Radiology, Dr. Suat Seren Chest Disease and Surgery Training and Research Hospital, Izmir, Turkey

\begin{abstract}
Objective: The most important factor for accurate treatment of patients with small cell lung carcinoma (SCLC) is accuracy of the initial staging. The aim of this study was to determine how often patients, staged as local or local-advanced disease by standard staging procedures (SSP), would be staged to have a metastatic disease based on the findings of the positron emission tomography-computed tomography (PET-CT) scan.

Methods: Patients with SCLC who were staged as I, II, or III disease by SSPs (according to the American Joint Committee on Cancer Staging, $7^{\text {th }}$ edition) formed the study population. SSPs included computed tomography of chest, abdomen, brain (or magnetic resonance imaging of brain), and bone scintigraphy. These patients were re-staged with ${ }^{18}$ F-FDG PET-CT scan.
\end{abstract}

Results: Between 2013 and 2015, 27 patients were prospectively studied. Of these patients, $92.5 \%$ were male and the median age was 61 . Among 27 patients, distant metastasis was detected by PET-CT in 7 (25.9\%) patients. Two of 7 patients were determined as stage IIIA by SSPs and 5 of 17 patients that were determined as stage IIIB by SSPs were upstaged to metastatic disease by PET-CT. All of the 7 patients had bone metastasis by PET-CT. But bone metastasis could not be detected with bone scintigraphy.

Conclusion: PET-CT detected distant metastasis in one quarter of SCLC stage III patients by SSPs. Patients who staged local-advanced SCLC with CT of the chest have to be assessed by PET-CT for extracranial distant metastasis.

Keywords: Metastasis, staging, positron emission tomography, small cell lung carcinoma

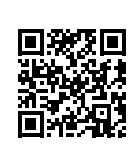

Received Date: 19.03.2016 Accepted Date: 13.06 .2016 Available Online Date: 05.09 .2016

DOI: 10.5152/ejp.2016.83007

Correponding Author

Ufuk Yilmaz

E-mail: ufukyilmazdr@gmail.com

- Available online at www.eurasianjpulmonol.com Commons Attribution-NonCommercial 4.0 International License.

\section{INTRODUCTION}

Lung cancer is one of the most common and lethal cancer among all cancers. Small cell lung carcinoma (SCLC) represents $15-20 \%$ of all lung cancers (1). Distant organ metastasis mostly exists at the initial diagnosis. As in all other cancers, the most important factor for accurate treatment is accuracy of the initial staging.

Currently, the main treatment modalities are systemic chemotherapy (C) and thoracic radiotherapy (RT) in limited disease-SCLC, except for very early stage diseases. The treatment policy is systemic chemotherapy in the disseminated disease. Five-year survival rates are $15-20 \%$ in limited disease cases and $1-2 \%$ in disseminated disease cases $(2,3)$. Possible inaccurate staging can be the cause of unnecessary RT, and its complications, or can be a reason not to undergo radiotherapy that can be beneficial.

Standard staging procedures (SSPs) including medical history, physical examination, computed tomography (CT) of the chest and upper abdomen to include adrenal glands, $\mathrm{CT}$ or magnetic resonance imaging (MRI) of the brain, and bone scintigraphy have been used as part of the initial evaluation of all newly diagnosed patients with $\operatorname{SCLC}(4,5)$. The positron emission tomography (PET) scan has important contributions on the diagnosis of solitary pulmonary nodules and staging or radiotherapy planning of non-small cell lung cancer (NSCLC) (6). Unnecessary thoracotomy, or local treatments, 
can be avoided with a PET-CT, which has detected distant metastasis in $10-20 \%$ of patients with NSCLC who were assessed as suitable for resection by SSPs (7).

At the time this study was activated, initial staging of newly diagnosed SCLC patients with PET or PET-CT was not standard care. Some studies with a small number of patients reported that $10-15 \%$ of patients with SCLC staged as limited disease status based on SSPs have migrated to extensive-stage disease status with the addition of PET scanning $(8,9)$.

The aim of this study was to determine how often patients with SCLC staged as local or local-advanced disease (stage I, II, or III) by SSPs would be staged to metastatic disease status (stage IV) based on the findings of PET-CT.

\section{METHODS}

We prospectively staged newly diagnosed by cytologically or histologically SCLC patients by SSPs. SSPs included medical history, physical examination, blood tests, contrast-enhanced (CE) CT of the chest and abdomen, CE-CT or MRI of the brain, and whole-body bone scintigraphy. All patients were staged according to the American Joint Committee on Cancer (AJCC) Staging Manual, $7^{\text {th }}$ edition (10). The patients who were staged as local or locally-advanced disease based on SSPs formed the study group. These patients were re-staged with ${ }^{18} \mathrm{~F}$-fluorodeoxyglucose (FDG) PET-CT according to the AJCC Staging, $7^{\text {th }}$ edition within a maximum of two weeks after SSPs were completed (10).

Patients with known former or present extra-thoracic second primary cancer, uncontrolled diabetes mellitus, hypersensitivity to contrast or radioactive substances, pregnancy, below 18 years of age, or had renal failure were excluded.

Contrast-enhanced-computed tomography of the chest, abdomen, and brain, and CE-MRI of the brain were interpreted by one of two radiologists. Lymph nodes $>1 \mathrm{~cm}$ on the short axis were accepted as positive for lymph node involvement. (99m) Tc-Methylene diphosphonate $(20-30 \mathrm{mCi})$ bone scans with a Philips bright-view double header camera were performed for bone metastasis. Hot spots were assessed based on all available patient information by one nuclear medicine physician. Results were reported as follows:

Group 1) negative for metastasis.

Group 2) doubtful for metastasis, might be degenerative/traumatic. Group 3) doubtful for metastasis, might be metastasis.

Group 4) positive for metastasis.

Patients in group 2 and 3 underwent further radiologic evaluation (CT or MRI) for metastasis. Finally, all data obtained from SSPs were evaluated for TNM staging by pulmonologists. Patients with local and local-advanced disease were imagined by PET-CT.

\section{PET-CT Imaging and Interpretation}

Whole-body ${ }^{18} \mathrm{~F}$-FDG PET-CT scaning was performed using the same protocol in the same institution (Philips Gemini TF 16 slices TOF). Patients received nothing by mouth for at least six hours preceding the PET-CT scan. Blood glucose levels were required to be less than $180 \mathrm{mg} / \mathrm{dL}$ before ${ }^{18} \mathrm{~F}-\mathrm{FDG}$ injection (3 MBq per kilogram of body weight). Sixty minutes after injection, PET images were acquired in axial planes from skull vertex to mid thigh. Time per bed position was 2:00 min for 5-7 bed positions. CT images were acquired in order to perform attenuation correction. Images were reconstructed in coronal, transverse, and sagittal planes. Standartized uptake value (SUV) for the region of interest (ROI) was decided using the maximum SUV $\left(S U V_{\text {max }}\right.$. The SUV $V_{\text {max }}$ indicates the highest single voxel SUV within the ROI. The lesions with SUV max $_{2.5}$ and lytic were considered as pathological.

Positron emission tomography-computed tomography images were interpreted based on all clinical informations by two nuclear medicine physicians blinded to the results of SSPs. The final PET interpretations were based on a consensus of the two observers. All patients were restaged according to the PET-CT findings by the same pulmonologists.

Ethical approval was received from the Local Ethics Committee of İzmir Dr. Suat Seren Chest Disease and Surgery Training and Research Hospital. Written informed consent was obtained from all patients.

\section{RESULTS}

Between January 2013 and March 2015, 27 patients with SCLC were included to the study, all of whom were staged as local to locally-advanced disease stage by SSPs and underwent re-staging by PET-CT. Of these patients, $92.5 \%$ were male and the median patient age was 61 years (range 42-83).

Distributions of patients according to the TNM system by SSPs and PET-CT are shown in Table 1. Stage groups are shown in Table 2.

Both staging methods indicated the same stage in stage II patients. Three of 7 patients (25.9\%) determined as stage IIIA by SSPs, were upstaged by PET-CT. One of 3 (3.7\%) patients had a contralateral lymph node metastasis (N3), 2 patients (7.4\%) had a metastatic disease. Five of 17 patients who were determined as stage IIIB by SSPs were upstaged to metastatic disease (M1b) by PET-CT (Table 2 ).

\begin{tabular}{|l|c|c|}
\hline \multicolumn{2}{|c|}{ Table 1. Comparison of TNM according to staging methods } \\
\hline T factor & SSPs (\%) & PET-CT staging (\%) \\
T1-2 & $5(18.5)$ & $6(22.3)$ \\
T3 & $6(22.3)$ & $7(25.9)$ \\
T4 & $16(59.2)$ & $14(51.8)$ \\
Lymph node & & \\
N0 & $3(11.2)$ & $2(7.4)$ \\
N1 & $1(3.7)$ & $1(3.7)$ \\
N2 & $18(66.6)$ & $11(40.7)$ \\
N3 & $5(18.5)$ & $13(48.2)$ \\
Metastasis & & $20(74.1)$ \\
M0 & $27(100)$ & $7(25.9)$ \\
M1 & 0 & \\
\hline
\end{tabular}

PET-CT: Positron emission tomography-computed tomography; SSPs: standard staging procedures 
Table 2. Comparison of the disease stage according to staging methods

\begin{tabular}{|l|c|c|}
\hline Stage & SSPs (\%) & PET-CT staging (\%) \\
\hline Stage I & 0 & 0 \\
Stage IIA & $2(7.4)$ & $2(7.4)$ \\
IIB & $1(3.7)$ & $1(3.7)$ \\
Stage IIIA & $7(25.9)$ & $4(14.8)$ \\
IIIB & $17(62.9)$ & $13(48.2)$ \\
Stage IV & 0 & $7(25.9)$ \\
PET-CT: Positron emission tomography-computed tomography; SSPs: standard \\
staging procedures
\end{tabular}

Table 3. Characteristics of the eight patients who had stage migration

\begin{tabular}{|l|c|c|c|c|c|c|}
\hline $\begin{array}{l}\text { Patient } \\
\text { no }\end{array}$ & SSPs & PET-CT & PET-CT & SSP & PET-CT & \\
\hline 2 & 2 & 2 & 1 & IIIB & IV & Multiple bone \\
3 & 2 & 2 & 1 & IIIA & IV & Multiple bone \\
4 & 2 & 3 & 0 & IIIA & IIIB & Contralateral MLNI \\
7 & 2 & 3 & 1 & IIIB & IV & Iliac bone Liver \\
12 & 2 & 2 & 1 & IIIB & IV & Vertebrae \\
13 & 2 & 2 & 1 & IIIB & IV & Femur \\
23 & 2 & 2 & 1 & IIIB & IV & Multiple bone \\
26 & 0 & 2 & 1 & IIIA & IV & Multiple bone \\
\hline
\end{tabular}

MLNI: Mediastinal lymph node involvement; PET-CT: positron emission tomography-computed tomography; SSPs: standard staging procedures

Table 4. Results of the comparison between SSPs and PET-CT

\begin{tabular}{|l|c|c|c|c|c|}
\hline PET-CT SSPs & Stage IIA & Stage IIB & Stage IIIA & Stage IIIB & Stage IV \\
\hline Stage IIA & $100 \%$ & 0 & 0 & 0 & 0 \\
Stage IIB & 0 & $100 \%$ & 0 & 0 & 0 \\
Stage IIIA & 0 & 0 & $57.1 \%$ & $14.2 \%$ & $28.5 \%$ \\
Stage IIIB & 0 & 0 & 0 & $70.5 \%$ & $29.5 \%$
\end{tabular}

PET-CT: Positron emission tomography-computed tomography; SSPs: standard staging procedures

Eight of 18 patients (29.6\%) who were found to have ipsilateral mediastinal lymph node involvement were detected to have contralateral mediastinal or supraclavicular lymph node involvement (N3) by PET-CT (Table 1). However, 2 of 8 patients (1 patient lymph node involvement, 1 patient metastasis) were upstaged by PET-CT. PET-CT did not show any stage migration due to T factors on the other 6 of 8 patients (22.2\%) who were staged IIIB disease by SSPs. However, 3 of these 6 patients were detected to have contralateral mediastinal lymph node involvement and 3 were detected to have supraclavicular lymph node involvement.

Positron emission tomography computed tomography showed bone metastasis in 7 of 27 patients (25.9\%) (Table 3), and these patients were upstaged to $\mathrm{M} 1 \mathrm{~b}$ disease. Bone scintigraphies in these $7 \mathrm{pa}-$ tients are the results of 3 patients in group 1 and 4 patients in group 2 or 3 . In 4 group 2 and 3 patients, the metastatic focuses detected by PET-CT were in different areas than sintigraphic hot spots evaluated as non-metastatic by additional radiological examinations. One additional patient (3.7\%) with N2 disease on CT was found to have contralateral lymph node involvement (N3) by PET-CT, and this patient was upstaged from IIIA to IIIB.

Stage agreements between SSPs and PET-CT for our study group with 27 patients are given in Table 4.

\section{DISCUSSION}

In this study, 7 of 27 SCLC patients (25.9\%) evaluated to have local or locally-advanced disease by SSPs were found to have distant metastasis with staging by PET-CT. Two of 7 patients staged as IIIA and 5 of 17 patients staged as IIIB by SSPs were upstaged to metastatic disease by PET-CT. One patient with stage IIIA was upstaged to IIIB by PET-CT. SSPs agreed with PET-CT in all stage II patients.

In studies thus far, distant metastasis was detected by PET-CT on the patients of $0-33 \%$ who were staged as limited disease SCLC by SSPs $(8,9,11-21)$. Seven of these studies were conducted retrospectively and 5 prospectively. Additionally in these studies, there were some differences in the selected imaging methods (PET or PET-CT). PET-CT was used in only one of the studies, 2 of the studies were performed by PET and PET-CT, and 9 used only PET.

The first meta-analysis about diagnostic performance of PET in staging of SCLC was published in 2014 and has shown that PET or PET-CT have a high diagnostic validity on assessing disease in SCLC patients. This meta-analysis reported no significant difference between PET and PET-CT (diagnostic validity of 0.94 and 0.93 , respectively) (22). Theorically, the deciding of anatomical projection of hot spots detected by PET is easier and more accurate with PET-CT fusion images. However, meta-analysis has not supported this conception (22).

Bradley et al. (8) prospectively found distant metastasis in 2 of 24 patients (8.3\%). Brink et al. (15) prospectively evaluated the staging value of PET and SSPs on 120 patients with SCLC and reported stage migrations in 13 patients (11\%). While 10 of these patients $(8.3 \%)$ were upstaged, 3 patients were downstaged. In another study of 18 patients with SCLC, 2 patients $(11.1 \%)$ staged as limited disease with SSPs were upstaged by PET scans (14). Kamel et al. (9) reported that 3 of 24 patients (13\%) staged as limited disease SCLC with SSPs were upstaged to dissemineted disease by PET. Schumacher et al. (13) reported that 7 of 26 SCLC patients (27\%) were detected to have disseminated disease by PET-CT.

In our study, we reported higher rates of stage changes (overall upstaging $29.6 \%$, upstaging due to distant metastasis was $25.9 \%$ ) compared to the other studies. This difference may originate from the use of PET-CT. However, Fischer et al. (11) also used PET-CT in their study and PET-CT showed distant metastasis in $10 \%$ of the patients who were determined as limited disease by SSPs. In this study, bone marrow biopsies were incorporated into conventional methods may be the cause of undetected distant metastasis with a low percent. In our study, all 7 patients (25.9\%) with distant metastasis by PET-CT had bone metastasis that could not be detected by bone scintigraphy. In study of Fischer et al. (11), 2 of 3 patents upstaged to IV showed bone 
metastasis by PET-CT. In this study, which compares PET-CT to bone scintigraphy and bone marrow biopsy, PET and PET-CT were found to have as high a sensitivity as bone scintigraphy and bone marrow biopsy (11). Lee et al. (23) reported that the sensitivity of PET-CT was $100 \%$ on a per-patient basis and $87 \%$ on a per-lesion basis; and there was no false-positive lesions on PET-CT images. In contrast, the sensitivity of the bone scan was $37 \%$ on a per-patient basis and $29 \%$ on a per-lesion basis. Twenty-one of 84 metastatic bone lesions were not detected by the initial bone scan, but were detected by PET-CT. Bone metastasis predominantly appears as lytic lesions in lung cancer. Patients with osteolytic metastasis not leading to blastic activity can be skipped with bone scintigraphy. PET-CT has a high sensitivity in detecting osteolytic metastasis.

In our study, one patient (3.7\%) determined as N0 by SSPs showed N2 disease, 8 patients (29.6\%) with N2 disease by SSPs displayed N3 disease with PET-CT. However, stages were not changed in 6 patients who were raised to N3 disease from N2. One patient was upstaged to IIIB from IIIA. While this situation is compatible with other studies, it also indicates that CT may not define well the involvement of lymph nodes. In a study that was researching the overall and disease-free survival rates in patients staged and not staged with PET against conventional staging alone, patients who were staged with PET had a higher nodal metastasis ( $74 \%$ vs $50 \%$ ) or N3 nodal metastasis ( $10 \%$ vs $0 \%$ in comparison with conventional staging (24).

In the present study, PET-CT did not further contribute on detecting brain metastasis. Kamel et al. (9) detected 2 patients with false negatives for brain metastasis in 24 SCLC patients. Vinjamuri et al. (18) reported that brain $\mathrm{MRI}$, or $\mathrm{CT}$, detected metastasis in 5 of 51 patients who had no brain metastasis by PET.

This study has some limitations. First of all, it has a small number of patients. A second limitation is the lack of histopathological confirmation of bone metastasis. Because the systemic treatment begins immediately in patients with SCLC, it is ethically diffucult to take a bone biopsy. The same difficulties are also valid for the verification of

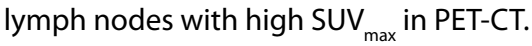

\section{CONCLUSION}

Positron emission tomography-computed tomography showed distant metastasis in one quarter of SCLC patients with stage III by SSPs. Patients who are staged with locally-advanced disease SCLC with CE-CT of the chest have to be assessed by PET-CT for extracranial metastasis.

Ethics Committee Approval: Ethics committee approval was received for this study from the ethics committee of İzmir Dr. Suat Seren Chest Disease and Surgery Training and Research Hospital.

Informed Consent: Written informed consent was obtained from patients who participated in this study.

Peer-review: Externally peer-reviewed.

Author Contributions: Concept - B.Y., U.Y., T.Ç., I.Y., S.A., B.G., H.K.; Design - B.Y., U.Y., T.Ç., I.Y., S.A., B.G., H.K.; Supervision - B.Y., U.Y., T.Ç., I.Y., S.A., B.G., H.K.; Resources - B,Y., U.Y., T.Ç., I.Y., S.A., B.G., H.K.; Materials - B.Y., U.Y., T.Ç., I.Y., S.A., B.G., H.K.; Data Collection and/or Processing - B.Y., U.Y.; Analysis and/or Interpretation - B.Y., U.Y.; Literature Search - B.Y., U.Y.; Writing Manuscript - B.Y., U.Y.; Critical Review - U.Y., B.Y.
Conflict of Interest: No conflict of interest was declared by the authors.

Financial Disclosure: The authors declared that this study has received no financial support.

\section{REFERENCES}

1. Jemal A, Bray F, Center MM, Ferlay J, Ward E, Forman D. Global cancer statistics. CA Cancer J Clin 2011; 61: 69-90. [CrossRef]

2. Thomson D, Hulse $P$, Lorigan $P$, Faivre-Finn $C$. The role of positron emission tomography in management of small cell lung cancer. Lung Cancer 2011; 73: 121-6. [CrossRef]

3. Foster NR, Qi Y, Shi Q, Krook JE, Kugler JW, Jett JR, et al. Tumor response and progression-free survival as potential surrogate endpoints for overall survival in extensive stage small-cell lung cancer: findings on the basis of North Central Cancer Treatment Group trials. Cancer 2011; 117: 1262-71. [CrossRef]

4. Kalemkerian GP. Staging and imaging of small cell lung cancer. Cancer imaging 2011; 11: 253-8. [CrossRef]

5. Rivera MP, Mehta AC, Wahidi MM. Establishing the diagnosis of lung cancer: Diagnosis and management of lung cancer, 3rd ed: American College of Chest Physicians Evidence-based clinical practice guidelines. Chest 2013; 143(5 Suppl): e142S-65S.

6. Mac Manus MP. Use of PET/CT for staging and radiation therapy planning in patients with non-small cell lung cancer. Q J Nucl Med Mol Imaging 2010; 54: 510-20.

7. Dooms C, Vansteenkiste J. Positron emission tomography in non-small cell lung cancer. Curr Opin Pulm Med 2007; 13: 256-60. [CrossRef]

8. Bradley JD, Dehdashti F, Mintun MA, Govindan R, Trinkaus K, Siegel BA. Positron emission tomography in limited-stage small-cell lung cancer: a prospective study. J Clin Oncol 2004; 22: 3248-54. [CrossRef]

9. Kamel EM, Zwahlen D, Wyss MT, Stumpe KD, von Schulthess GK, Steinert HC. Whole-body (18) F-FDG PET improves the management of patients with small cell lung cancer. J Nucl Med 2003; 44: 1911-7.

10. Edge SB, Compton CC. The American Joint Committee on Cancer: the 7th edition of the AJCC cancer staging manual and the future of TNM. Ann Surg Oncol 2010; 17: 1471-4. [CrossRef]

11. Fischer BM, Mortensen J, Langer SW, Loft A, Berthelsen AK, Petersen BI, et al. A prospective study of $\mathrm{PET} / \mathrm{CT}$ in initial staging of small cell lung cancer: comprasion with $\mathrm{CT}$, bone scintigraphy and bone marrow analysis. Ann Oncol 2007; 18: 338-45. [CrossRef]

12. Kut V, Spies W, Spies S, Gooding W, Argiris A. Staging and monitoring of small cell lung cancer using [18F]fluoro-2-deoxy-D-glucose-positron emission tomography (FDG-PET). Am J Clin Oncol 2007; 30: 45-50. [CrossRef]

13. Schumacher T, Brink I, Mix M, Reinhardt M, Herget G, Digel W, et al. FDGPET imaging for the staging and follow-up of small cell lung cancer. Eur J Nucl Med 2001; 28: 483-8. [CrossRef]

14. Chin R Jr, McCain TW, Miller AA, Dunagan DP, Acostamadiedo J, Douglas Case $L$, et al. Whole body FDG-PET for the evaluation and staging of small cell lung cancer: a preliminary study. Lung Cancer 2002; 37: 1-6. [CrossRef]

15. Brink I, Schumacher T, Mix M, Ruhland S, Stoelben E, Digel W, et al. Impact of [16F] FDG-PET on the primary staging of small-cell lung cancer. Eur J Nucl Med Mol Imaging 2004; 31: 1614-20. [CrossRef]

16. Shen YY, Shiau YC, Wang JJ, Ho ST, Kao CH. Whole body 18F-2-deoxyglucose positron emission tomography in primary staging small cell lung cancer. Anticancer Res 2002; 22: 1257-64.

17. Pandit N, Gonen M, Krug L, Larson SM. Prognostic value of [18F]FDG-PET imaging in small cell lung cancer. Eur J Nucl Med Mol Imaging 2003; 30: 7884. [CrossRef]

18. Vinjamuri M, Craig M, Campbell-Fontaine A, Almubarak M, Gupta N, Rogers JS. Can positron emission tomography be used as a staging tool for small-cell lung cancer? Clin Lung Cancer 2008; 9: 30-4.

19. Azad A, Chionh F, Scott AM, Lee ST, Berlangieri SU, White S, et al. High impact of 18F-FDG-PET on management and prognostic stratification of newly diagnosed small cell lung cancer. Mol Imaging Biol 2010; 12: 443-51. [CrossRef] 
20. Niho S, Fujii H, Murakami K, Nagase S, Yoh K, Goto K, et al. Detection of unsuspected distant metastases and/or regional nodes by FDG-PET (corrected) scan in apparent limited disease small cell lung cancer. Lung Cancer 2007; 57(3): 328-33. [CrossRef]

21. Blum R, MacManus MP, Rischin D, Michael M, Ball D, Hicks RJ. Impact of positron emission tomography on the management of patients with small-cell lung cancer: preliminary experience. Am J Clin Oncol 2004; 27: 164-71. [CrossRef]

22. Lua YY, Chene JH, Liang JA, Chu S, Lin WY, Kao CH. 18F-FDG PET or $\mathrm{PET} / \mathrm{CT}$ for detecting extensive disease in small-cell lung cancer: a systematic review and meta-analysis. Nucl Med Commun 2014; 35: 697-703. [CrossRef]

23. Lee JW, Lee SM, Lee HS, Kim YH, Bae WK. Comparison of diagnostic ability between $(99 \mathrm{~m}) \mathrm{TC}-\mathrm{MDP}$ bone scan and (18)F-FDG PET/CT for bone metastasis in patients with small cell lung cancer. Ann Nucl Med 2012; 26: 627-33. [CrossRef]

24. Xanthopoulos EP, Corradetti MN, Mitra N, Fernandes AT, Kim M, Grover S, et al. Impact of PET staging in limited-stage small-cell lung cancer. J Thorac Oncol 2013; 8: 899-905. [CrossRef] 